Chirurgia (2018) 113: 720

No. 5, September - October

Copyright $($ Celsius

http://dx.doi.org/10.21614/chirurgia.113.5.720

\title{
Reply to the Letter to the Editor: Comment to Jejunal Diverticulitis Mimicking Small Bowel Perforation: Case Report and Review of the Literature
}

\section{Athanasios Syllaios}

Department of Surgery, General Hospital of Lamia, Greece

Corresponding author:

Athanasios Syllaios, MD

Kountourioti 5, Lamia 35100, Greece

E-mail: nh_reas@hotmail.com
Dear Editor,

We thank the authors of this letter to the editor for the valuable information that they provided. We are familiar to the fact that conservative management is gaining ground against surgical treatment and this fact is mentioned in our article. This fact is better highlighted through the references that the authors of the letter to the editor provided and their comments. 